\title{
High postoperative risk after pneumonectomy in elderly patients with right-sided lung cancer
}

\author{
J.P. van Meerbeeck*, R.A.M. Damhuis" ${ }^{\#}$ M.L. Vos de Wael ${ }^{\#}$
}

High postoperative risk after pneumonectomy in elderly patients with right-sided lung cancer. J.P.van Meerbeeck, R.A.M. Damhuis, M.L. Vos de Wael. (C)ERS Journals Ltd 2002. ABSTRACT: The present study investigated postoperative mortality (POM), its predictors and relationship with long-term survival in patients who underwent surgery for lung cancer.

The 30-day mortality after thoracotomy in 1,830 patients from the Flemish multicentre hospital-based lung cancer registry was analysed according to patient, tumour, treatment and hospital characteristics and compared with 5-yr survival figures for the same patients.

Overall POM was 4.4\%. In univariate analysis age, extent of surgery and low hospital volume were associated with a higher POM. In multiple regression analysis age, extent of surgery and side of the pneumonectomy proved to be independent predictors of POM. In patients aged $>70$ yrs who underwent right-sided pneumonectomy POM was $17.8 \%$.

Overall, mortality was comparable to published series from referral centres. Age and extent of resection are the main predictors of postoperative mortality in lung-cancer patients. In the operable elderly patient, age alone does not justify denying the survival benefit experienced by resection of lung cancer. The high mortality after right-sided pneumonectomy in elderly patients warrants caution, as the treatment benefit may become marginal.

Eur Respir J 2002; 19: 141-145.
*University Hospital Rotterdam, Dept of Pulmonology and "Comprehensive Cancer Centre Rotterdam, Dept of Research, Rotterdam, the Netherlands.

Correspondence: J.P. van Meerbeeck, University Hospital Rotterdam, Dept of Pulmonology, PO Box 5201, 3008 AE Rotterdam, the Netherlands. Fax: 31104634856

\section{Keywords: Elderly}

lung cancer

mortality

pneumonectomy

surgery

Received: March 152001

Accepted after revision September 13 2001
Lung cancer is the leading cause of cancer death in the Western world. The age standardized mortality rate for males in the Flemish region of Belgium (population 6 million people) is $113 \cdot 100,000$ inhabitants $^{-1}$. More than 3,500 cases a year are diagnosed, of which $63 \%$ will die within a year [1]. The frequency distribution of lung cancer is highest in the seventh decade. Surgical resection is considered to be the single curative treatment in nonsmall cell lung cancer, provided the procedure is radical and complete. Nevertheless, $<50 \%$ of patients are alive $\geqslant 5$ yrs after resection.

Unfortunately, some patients die shortly after surgery, despite intensive preoperative assessment. The fraction of patients dying within 30 days of operating is defined as the "postoperative mortality" (POM). The POM associated with lung-cancer surgery has aroused controversy in the literature, as only the best surgeons and hospitals are likely to participate in multicentre studies and report their experience causing a skew towards better results. Furthermore, since POM is reported to increase with age and the proportion of elderly lung-cancer patients is currently increasing, survival benefit might become marginal.

In order to address these issues, the POM of patients registered in a large regional multicentre hospital registry of lung-cancer cases was studied and compared to the survival data of the same population.

\section{Patients and methods}

\section{Database}

In Flanders, Belgium, a multicentre hospital registry of newly diagnosed, histologically proven lung-cancer cases has been in use since March 1, 1990. Contributors to this registry are mainly pulmonologists and thoracic surgeons, assisted by a trained registration nurse. Patients entered in the registry represent a proper sample of lung cancer as it is diagnosed and treated in 52 community and university hospitals throughout the Flemish region.

The layout of the registry has been presented elsewhere [2]. Briefly, a selection of clinical, histological, endoscopic, radiological and staging data are collected, together with information on first treatment(s). The variables considered are sex, age, World Health Organization (WHO) Performance Score, smoking status at diagnosis, histological type, site and side of the tumour. Data on cardiac comorbidity and pulmonary function are not collected. In patients undergoing surgery, information on type and extent of resection and pathological staging according to the tumour, node, metastasis (TNM) classification [3] is available. The number of thoracotomies performed at a particular centre is used as an index of experience in thoracic surgery. POM is defined as death from any 
cause within 30 days after resection of lung cancer, regardless of whether death occurred in or outside the hospital. Survival data are validated either by the registering physician, or at the civil registry office.

\section{Statistical analysis}

POM was calculated as the fraction of patients dying over the total number of patients with the same characteristic. Confidence intervals $(95 \% \mathrm{CI})$ around the point estimates are calculated as exact intervals for binomial proportions [4]. Univariate analysis of continuous variables was performed using an unpaired t-test. A Chi-squared test was used to determine the significance for discrete variables, with appropriate use of Yate's correction for small numbers. The Mantel-Haenzel trend test was used for the evaluation of ordinal variables. Multivariate analysis was performed using a logistic regression model. Discrete variables were represented by indicator variables and their predictive value was assessed with the p-value of the log likelihood. Only variables significantly improving the fit of the model $(\mathrm{p}<0.05)$ were included in the final model. Due to statistical interaction between side and pneumonectomy, right and left pneumonectomy were entered separately in the model. Survival estimates were calculated according to the KaplanMeier method and compared using the log-rank test. Patients dying within 1 month of resection were excluded from the survival analysis.

\section{Results}

From January 1990-November 1996, 8,063 patients with a primary bronchogenic carcinoma were entered in the registry. Of these, $1,830(23 \%)$ underwent thoracotomy. In 100 patients $(5.5 \%)$, no resection was performed. In all other patients, various procedures were undertaken to resect the cancerous lesion. The median age was 64 yrs (SD 8 yrs) and $89 \%$ of the patients were males. Patients undergoing pneumonectomy were significantly younger (64 yrs) than those undergoing bilobectomy $(67 \mathrm{yrs} ; \mathrm{p}<0.01)$ or lobectomy $(66 \mathrm{yrs} ; \mathrm{p}<0.01)$. Of the patients undergoing pneumonectomy, $24 \%$ were aged $\geqslant 70 \mathrm{yrs}$, compared to $29 \%$ of those subjected to lobectomy and $35 \%$ of the bilobectomy cases.

Eighty-one patients $(4.4 \%)$ died within 30 days of their operation. The POM according to various patient, tumour, treatment and hospital characteristics is given in table 1 . Sex, performance score according to the WHO definition and smoking status did not affect the POM. In the youngest $(<60 \mathrm{yrs})$ patients, POM was $2.2 \%$, doubling in the seventh decade, and increasing further with age to $6.7 \%$ in the oldest group $(<0.01)$. Central versus peripheral location of the primary tumour had no apparent influence and neither did morphology and postsurgical stage. No POM was seen following resection of carcinoid tumours. The most striking difference related to the extent of resection was that with increasing loss of lung parenchyma, POM rate rose from $1.5 \%$ to $7.2 \%$ $(p<0.01)$. Finally, hospital volume, defined as the annual number of resections performed per institution and used as an index of thoracic surgical experience, had a small influence on POM. The highest POM was seen in patients subjected to right-sided pneumonectomy, in whom it was more than double that of leftsided pneumonectomy $(\mathrm{p}<0.01)$ (table 2$)$. The prognostic effect of tumour side was not seen with lesser resections. Chest-wall resection and extensive mediastinal lymph node dissection were not significantly associated with a higher POM than uncomplicated resection.

In multiple regression analysis, age, extent and side of resection were independently associated with a higher 30-day mortality (table 3). Compared to the youngest group, the odds ratio (OR) for patients aged $60-69$ yrs was 2.1 and 3.3 for patients aged $\geqslant 70$ yrs. Compared to smaller resections, the OR for bilobectomy and left pneumonectomy were both 1.5 and for right pneumonectomy the OR was 4.2.

After exclusion of postoperative deaths, 5-yrs survival rates were 33\% after pneumonectomy, 50\% after bilobectomy and $54 \%$ after lobectomy $(\mathrm{p}<0.01)$ (fig. 1) Long-term survival was similar after right and left pneumonectomy $(\mathrm{p}=0.69)$. Controlling for type of resection, 5-yr survival was similar for patients aged $60-69$ yrs and $\geqslant 70$ yrs $(p=0.43)$ but better for those aged $<60$ yrs $(\mathrm{p}<0.01)$.

\section{Discussion}

In this multi-institutional study an overall POM of $4.4 \%$ was observed which is comparable to the $3.7 \%$ reported in the landmark article by GinsBERG et al. [5]. Based upon the combined experience of referral centres of the Lung Cancer Study Group, it was stated that "pneumonectomies should carry a risk of less than $7 \%$, lobectomies less than $3 \%$, and lesser resections less than $2 \% "$. More recent studies reported a much higher POM in community hospitals $[6,7]$ and general results may be even worse due to publication bias. For a meaningful comparison between series, studies should have a sufficient sample size and a uniform definition of POM. Also, given the varying proportions of elderly patients and pneumonectomies in different centres, it is suggested that results should be reported by age group and extent of resection (table 4).

Multivariate analysis showed that age, extent of resection and side of the pneumonectomy were independent prognostic factors. The prognostic influence of age has been confirmed in many reports but was recently disputed by a "Swiss" study with standard complication rates but a very low operative mortality, even in the elderly [8]. This would suggest that early detection and adequate treatment of complications can be beneficial. Age itself probably reflects other prognostic factors such as comorbidity and cardiovascular and pulmonary function, information which was not available in the present study. FERGUSON and KARRISON [9] identified the carbon monoxide diffusing capacity of the lung $(D \mathrm{~L}, \mathrm{CO})$ and preoperative hypertension as important risk factors. 
Table 1.-Postoperative mortality (POM) for various characteristics in 1,830 patients with lung cancer

\begin{tabular}{|c|c|c|c|c|}
\hline & & Patients n & POM \% & $\mathrm{p}$-value \\
\hline \multirow[t]{2}{*}{ Gender } & Male & 1625 & 4.8 & 0.07 \\
\hline & Female & 205 & 2.0 & \\
\hline \multirow[t]{4}{*}{ WHO performance score } & 0 & 697 & 3.6 & $0.14^{\#}$ \\
\hline & 1 & 760 & 4.6 & \\
\hline & $\geqslant 2$ & 70 & 7.1 & \\
\hline & Unspecified & 303 & 5.3 & \\
\hline \multirow[t]{4}{*}{ Smoking status } & Current & 973 & 4.3 & 0.40 \\
\hline & $E x>1 \mathrm{yr}$ & 627 & 5.1 & \\
\hline & Never & 121 & 1.7 & \\
\hline & Unspecified & 109 & 4.6 & \\
\hline \multirow[t]{3}{*}{ Age yrs } & $<60$ & 459 & 2.2 & $0.01^{\#}$ \\
\hline & $60-69$ & 876 & 4.3 & \\
\hline & $\geqslant 70$ & 495 & 6.7 & \\
\hline \multirow[t]{3}{*}{ Site } & Central & 1038 & 4.8 & 0.37 \\
\hline & Peripheral & 712 & 3.7 & \\
\hline & Unspecified & 80 & 6.3 & \\
\hline \multirow[t]{3}{*}{ Morphology } & Squamous cell & 1106 & 5.0 & 0.13 \\
\hline & Adenocarcinoma & 363 & 2.5 & \\
\hline & Other & 361 & 4.7 & \\
\hline \multirow[t]{4}{*}{ Pathological stage } & I & 953 & 3.8 & $0.19^{\#}$ \\
\hline & II & 256 & 3.9 & \\
\hline & III-IV & 447 & 5.4 & \\
\hline & Unknown & 174 & 6.3 & \\
\hline \multirow[t]{6}{*}{ Type of resection } & Pneumonectomy & 657 & 7.2 & $<0.01$ \\
\hline & Bilobectomy & 153 & 4.6 & \\
\hline & Lobectomy & 804 & 2.5 & \\
\hline & Segmental/wedge & 68 & 1.5 & \\
\hline & Exploration & 100 & 4.0 & \\
\hline & Unspecified & 48 & 4.2 & \\
\hline \multirow[t]{4}{*}{ Hospital volume } & $1-4$ & 319 & 6.9 & $0.05^{\#}$ \\
\hline & $5-14$ & 561 & 4.1 & \\
\hline & $15-34$ & 552 & 4.0 & \\
\hline & $\geqslant 35$ & 398 & 3.5 & \\
\hline Total & & 1830 & 4.4 & \\
\hline
\end{tabular}

WHO: World Health Organization; ${ }^{\#}$ : Mantel-Haenszel Chi-squared trend test; ${ }^{\curvearrowleft}$ : annual number of resections per institution.

The authors failed to establish the prognostic value of the WHO performance status and a study by KOHMAN et al. [10] previously showed that, even with a wide range of biological indicators, it is difficult to determine prognostic factors. Given the modern level of postoperative mortality, evaluation of the intrinsic value of these biological factors will require very large studies and uniform registration of many risk factors. At present, however, risk evaluation for surgery will still be based on a clinical assessment of cardiopulmonary function and comorbidity rather than on age alone.

Table 2.-Postoperative mortality (POM) in special subgroups

\begin{tabular}{lcr}
\hline & Patients n & POM \% \\
\hline Side of surgery & & \\
Right pneumonectomy & 293 & 10.6 \\
Left pneumonectomy & 355 & 3.9 \\
Pneumonectomy, side not specified & 9 & 22.2 \\
Type of surgery & 26 & 11.5 \\
Incomplete resection & 47 & 4.3 \\
Chest wall resection & 88 & 6.8 \\
Mediastinal lymph node dissection & \\
\hline
\end{tabular}

The prognostic value of extent of surgery is widely known and even in patients with sufficient pulmonary reserve, (bi)lobectomy is preferred to pneumonectomy. As a long-term consequence of pneumonectomy, pulmonary hypertension and progression of emphysema may occur. Survival may appear to be poorer after pneumonectomy but this is mainly due to confounding by stage [9]. Minimal operations such as wedge and segmental resections are sometimes performed in patients with limited pulmonary reserve

Table 3. - Multivariate evaluation of prognostic factors for postoperative mortality

\begin{tabular}{lcc}
\hline & Odds ratio & $95 \% \mathrm{CI}$ \\
\hline $\begin{array}{l}\text { Age yrs } \\
\quad 60\end{array}$ & 1 & \\
$\quad 60-69$ & 2.1 & $1.0-4.4$ \\
$\quad \geqslant 70$ & 3.3 & $1.6-7.0$ \\
Type of resection & & \\
$\quad$ Right pneumonectomy & 4.2 & $2.4-7.2$ \\
$\quad$ Left pneumonectomy & 1.5 & $0.7-2.8$ \\
Bilobectomy & 1.5 & $0.6-3.6$ \\
Other & 1 & \\
\hline
\end{tabular}

CI: confidence interval. 


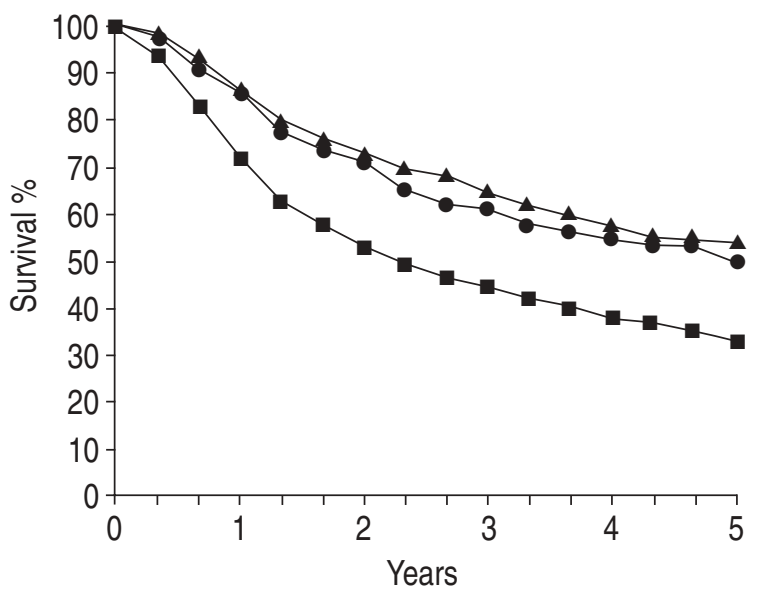

Fig. 1.-Survival for patients with nonsmall cell lung cancer by type of surgery, excluding postoperative deaths. $\boldsymbol{\Delta}$ : lobectomy; : bilobectomy; $\mathbf{\square}$ : pneumonectomy.

at the risk of increasing local recurrence rates. Exploratory thoracotomies were previously described as high-risk operations [11] but this is challenged by the $4 \%$ POM in the authors series.

One of the striking findings in this study is the significant difference in POM between right-sided and left-sided pneumonectomy. This side-specific difference is not present for lesser resections and has been previously reported by several authors. In 1974, Weiss [12] reported a difference of $20 \%$ versus $8 \%$ and in 1984 Nagasaki et al. [13] published a difference of $13 \%$ versus $0 \%$. This was again confirmed by WAHI et al. [14] in 1989, 14\% versus 1\%, and Au et al. [15], 37\% versus $6 \%$, and the present results of $11 \%$ versus $4 \%$ confirm that this is not a spurious finding from subgroup analysis. Similar findings were also recently observed after induction chemotherapy [16] and cannot be fully explained by the larger volume of the right lung. After right pneumonectomy, pulmonary pressure may be increased which could explain the higher rate of dysrhythmias [17] and occasionally this may even lead to an interatrial shunt through a patent foramen ovale [18]. A higher frequency of complications such as bronchopleural fistula and empyema has also been reported for right-sided operations [19] and the importance of adequate coverage of the bronchial stump needs to be stressed. Postpneumonectomy syndrome with mediastinal shift is diagnosed mainly after right pneumonectomy but can be prevented by adequate filling of the hemithorax. Postoperative pulmonary oedema has been described more frequently after right pneumonectomy but this was recently questioned [20].

The highest operative risk $(17.8 \%)$ was observed in patients aged $\geqslant 70$ yrs undergoing pneumonectomy for right-sided lung cancer. Older reports caution for surgery when POM equals survival [21]. When proposing a major surgical procedure to a patient, one always has to consider whether the gain in 5-yr survival outweighs the potential short-term risk of the intervention. This is particularly true in elderly patients who combine a higher operative risk with shorter life expectancy. However, the 5-yr survival probability of nonsurgically treated patients with stage I lung cancer is $\leqslant 10 \%$ and the life expectancy at 70 yrs in Western Europe is still 13 yrs. Considering the fact that 5-yr survival after pneumonectomy is reasonable, the present authors agree with most authors that older age should not be the only reason to withhold surgical therapy $[8,22]$. In a disease like lung cancer, resection may even be proposed to octogenarians, although results are contradictory $[23,24]$. Independent of age, patients need to be informed about the operative risk because, even when a lobectomy is anticipated, more extensive surgery may be necessary.

In the near future, lung-cancer surgery will be characterized by increasing numbers of elderly patients, requiring, more extensive resections, often preceded by chemo- and/or radiotherapy. The latter induction procedures make surgical intervention technically more difficult, and the likelihood of exploratory thoracotomy without resection will increase. Results from two early studies report a POM of $3-6 \%[25,26]$ but it may be expected that with increasing use of multimodality treatment, figures will rise substantially, especially after pneumonectomy [27]. In high-risk patient, additional attention is needed in the postoperative phase and referral to larger hospitals may be judicious. Surgical experience, measured by the number of resections per year, has been identified as an independent prognostic factor but the authors results on this point were negative, as was a recent study from the USA [28]. As high-risk patients tend to be referred to larger centres, the volume issue should be evaluated in studies with more detailed information on comorbidity.

To conclude, the present day postoperative mortality in patients with lung cancer, treated in a community setting, is acceptable. However further monitoring is warranted. The extent of surgical intervention as

Table 4. - Proposed standards for reporting postoperative mortality (POM) by age group and type of resection

\begin{tabular}{lcrr}
\hline & \multicolumn{2}{c}{ Age yrs } & $\geqslant 70$ \\
\cline { 2 - 4 } & \multicolumn{1}{c}{$<0$} & $60-69$ & $17.8(9.8-28.5)$ \\
\hline Right pneumonectomy & $4.8(1.3-11.9)$ & $10.2(5.7-16.6)$ & $8.1(3.3-16.1)$ \\
Left pneumonectomy & $0(-)$ & $4.1(1.7-8.3)$ & $3.7(0.5-12.7)$ \\
Bilobectomy & $0(-)$ & $6.9(2.3-15.3)$ & $3.9(2.0-6.9)$ \\
Lesser resections & $2.4(0.9-5.1)$ & $2.4(1.3-4.2)$ & 3 \\
\hline
\end{tabular}

Data are presented as POM $\%$ (95\% confidence interval). 
well as the age of the patient are independent predictors and patients in whom right-sided resection with optional pneumonectomy is envisaged, should be carefully selected and instructed about the risk of the procedure. The authors recommend that such procedures should preferably be carried out in experienced centres.

\begin{abstract}
Acknowledgements. The authors would like to thank M. Fortuin, J. Weyler, J. Vansteenkiste, J. Aumann, G. Deneffe, M. Haelterman, D. Galdermans, G. Joos, M. Noppen, P. Pinson, L. Vandewalle on behalf of the Task Group on Lung Cancer-VRGT, Eendrachtstraat 56, B-1050 Brussels.
\end{abstract}

\section{References}

1. Vansteenkiste J, Weyler J, Deneffe G, et al. Bronchusearcinoom in Vlaanderen. Tijdschr Gencesk 1995; 51: 1009-1019.

2. Van Meerbeeck J, Weyler J, Uydebrouck M, et al. The lung cancer registration project in Flanders (Belgium): an interim analysis of the first 100 cases. Lung Cancer 1991; 8: 5s.

3. Mountain CF. A new international staging system for lung cancer. Chest 1986; 89: 225s.

4. Newcombe RG. Two-sided confidence intervals for the single proportion: comparison of seven methods. Statist Med 1998; 17: 857-872.

5. Ginsberg RJ, Hill LD, Eagan RT, et al. Modern thirty-day operative mortality for surgical resection in lung cancer. J Thorac Cardiovasc Surg 1983; 86: 654 658.

6. Romano PS, Mark DH. Patient and hospital characteristics related to in-hospital mortality after lung cancer resection. Chest 1992; 101: 1332-1337.

7. Whittle J, Steinberg EP, Anderson GF, Herbert R. Use of Medicare claims to evaluate outcomes in elderly patients undergoing lung resection for lung cancer. Chest 1991; 100: 729-734.

8. Bernet F, Brodbeck R, Guenin M, et al. Age does not influence early and late tumor-related outcome for bronchogenic carcinoma. Ann Thorac Sur 2000; 69: 913-918.

9. Ferguson MK, Karrison T. Does pneumonectomy for lung cancer adversely influence long-term survival. J Thorac Cardiovasc Surg 2000; 199: 440-448.

10. Kohman U, Meyer JA, Ikins PM, Oates RP. Random versus predictable risks of mortality after thoracotomy for lung cancer. J Thorac Cardiovasc Surg 1986; 91: $551-554$

11. Mittman C, Bruderman I. Lung cancer: to operate or not? Am Rev Respir Dis 1977; 116: 477-496.

12. Weiss W. Operative mortality and five year survival rates in patients with bronchogenic carcinoma. Am J Surg 1974; 128: 779-804.

13. Nagasaki F, Flehinger BJ, Martini N. Complications of surgery in the treatment of carcinoma of the lung. Chest 1982; 82: 25-29.

14. Wahi R, McMurtrey MJ, DeCaro LF, et al. Determinants of perioperative morbidity and mortality after pneumonectomy. Ann Thorac Surg 1989; 48: 33-37.

15. Au J, El Oakley R, Cameron EWJ. Pneumonectomy for bronchogenic carcinoma in the elderly. Eur $J$ Cardiothorac Surg 1994; 8: 247-250.

16. Abolhoda A, Martin J, Ginsberg RJ, et al. Morbidity and mortality after pulmonary resections in lung cancer after induction treatment. Lung Cancer 2000; 29: 89 s.

17. Harpole DH, Liptay MJ, DeCamp MM Jr, Mentzer SJ, Swanson SJ, Sugarbaker DJ. Prospective analysis of pneumonectomy: risk factors for major morbidity and cardiac dysrhythmias. Ann Thorac Sur 1997; 63: 198-201.

18. Bakris NC, Siddiqi AJ, Fraser CD, Mehta AC. Rightto-left interatrial shunt after pneumonectomy. Ann Thorac Surg 1997; 63: 198-201.

19. Wright CD, Wain JC, Mathisen DJ, Grilo HC. Postpneurnonectomy bronchopleural fistula after sutured bronchial closure: incidence, risk factors, and management. J Thorac Cardiovasc Surg 1996; 112: $1367-1371$.

20. Jordan S, Mitchell JA, Quinlan GJ, Goldstraw P, Evans TW. The pathogenesis of lung injury following pulmonary resection. Eur Respir J 2000; 15: 790-799.

21. McNeil BJ, Weichselbaum R, Pauker SG. Fallacy of the five-year survival in lung cancer. $N$ Engl $J$ Med 1978; 229: 1397-1401.

22. De Perrot M, Licker M, Reymond MA, Robert J, Spiliopoulos A. Influence of age on operative mortality and long-term survival after lung resection for bronchogenic carcinoma. Eur Respir J 1999; 14: 419422 .

23. Naunheim KS, Kesler KA, d'Orazio SA, Fiore AC, Judd DR. Lung cancer surgery in the octogenarian. Eur J Cardiothorac Surg 1994; 8: 453-456.

24. Shirakusa T, Tsutrmui M, Iriki N, et al. Results of resection for bronchogenic carcinoma in patients over the age of 80. Thorax 1989; 44: 189-191.

25. Rosell R, Gomez-Codina J, Camps C, et al. A randomized trial comparing preoperative chemotherapy plus surgery with surgery alone in patients with non-small cell lung cancer. N Engl J Med 1994; 330: 133-158.

26. Roth JA, Fossella F, Kornaki R, et al. A randomized trial comparing preoperative chemotherapy and surgery with surgery alone in respectable stage IIIA nonsmall cell lung cancer. J Natl Cancer Inst 1994; 86: 673-680.

27. Fowler WC, Langer CJ, Curran WJ, Keller SM. Postoperative complications after combined neoadjuvant treatment of lung cancer. Ann Thorac Surg 1993; 55: 986-989.

28. Begg CB, Cramer LD, Hoskins WJ, Brennan MF. Impact of hospital volume on operative mortality for major cancer surgery. JAMA 1998; 280: 1747-1751. 